\title{
Pode-se Planejar a Paisagem?
}

Paulo R. M. Pellegrino

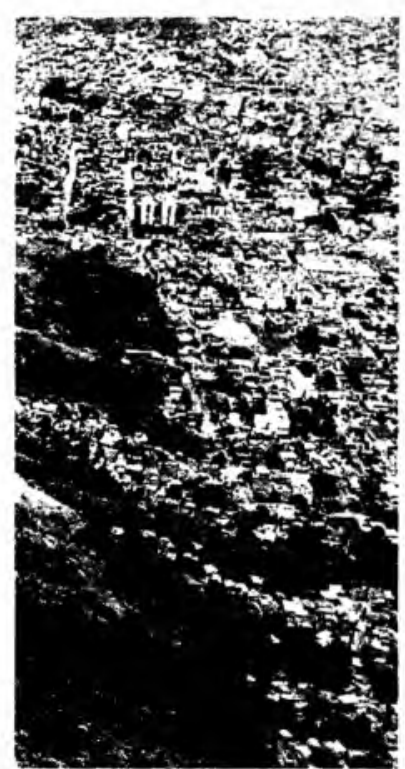

Arquiteto-paisagista, professor doutor junto ao grupo de disciplinas Paisagem e Ambiente do Departamento de Projeto da Faculdade de Arquitetura e Urbanismo da Universidade de São Paulo - FAUUSP 
A aplicação dos principios da ecologia da paisagem no planejamento e projeto paisagistico pode integrar esquematicamente todas as dimensões na paisagem que são espacialmente explícitas, como a cultural, estética e socioeconômica com a dimensão ambiental. Estes principios oferecem uma teoria e uma evidència empírica para o entendimento e comparação entre diferentes configurações espaciais, que nos permite enfrentar a questão central: qual é o arranjo ótimo do uso do solo numa paisagem?

The spatial solution outlined by landscape ecology principles as applied to landscape planning and design could mesh ecological integrity and basic human needs and help us answer the central question: what is the optimum arrangement of land uses in a landscape?

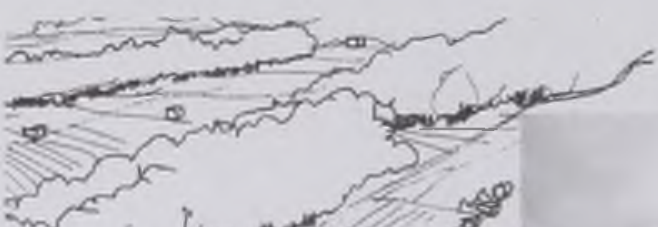




\section{Pode-se Planejar a Paisagem?}

Nas escolas de arquitetura e urbanismo brasileiras que tiveram uma forte tradição de planejamento urbano e regional, o título deste artigo - como uma pergunta - talvez seja necessário, quando se quer discutir a organização dos espaços livres na escala do mosaico de paisagens.

Isso se deve, em grande parte, à experiência havida até os anos 80 do século passado, quando a preponderância do papel do Estado na determinação das políticas de desenvolvimento e de intervenção no território assegurava aos planejadores um considerável papel entre as forças que atuavam na formação do espaço brasileiro. Os planos produzidos então, dentro da linha desenvolvimentista vigente, apresentavam quase sempre uma exclusiva perspectiva socioeconômica, com a dimensão espacial basicamente se limitando aos aspectos locacionais dos investimentos públicos e das atividades produtivas, como parte de uma estratégia nacional.

Depois, nos anos 90 , com a retirada do Estado da função de centralizar essas ações, foi praticamente desmantelada a estrutura de planejamento existente em seus vários níveis. Isso ocasionou uma lacuna, que o estágio de desenvolvimento do país fez potencializar, levando a uma sensação de perda do controle que, ainda que tivesse eficácias variáveis, faz-se necessário para uma organização dos espaços urbanos e rurais com uma visão a mais longo prazo. Um dos poucos instrumentos de ação nesse sentido passa a ser legislação ambiental que é então consolidada, com suas ferramentas de licenciamento e avaliação de impactos ambientais das atividades, além de algumas posturas locais mais ou menos efetivas. Mas estes dispositivos legais se mostraram insuficientes para apreender o sentido das práticas sociais definidoras dos usos do espaço e, deste modo, garantir um efetivo atendimento às demandas da sociedade que fosse adequádo às condicionantes da natureza.

Dessa forma, quando entendemos ser a sustentabilidade das cidades somente possível quando esta é vista como parte indivisível de uma constelação de paisagens conectadas, que devem ser planejadas e protegidas em seu conjunto, uma rápida incursão na evolução desse entendimento em nosso meio e em outras realidades, talvez nos auxilie a entender a especi-ficidade dessa atividade de planejamento, e a discutir sua viabilidade entre nós.

\section{A Dimensão Ambiental da paisagem}

A leitura da paisagem original, dos seus ecossistemas e dos recursos que abrigam e que garantem a habitabilidade da cidade, torna-se mais difícil de ser plenamente alcançada pela população dentro das áreas urbanizadas e demais espaços intensamente processados. $\mathrm{A}$ isto 
se associa uma metódica, planejada e desejada exclusão, por grande parte do espectro social da população, da paisagem anterior e dos seus condicionantes ambientais na construção das nossas cidades. Esse estado de coisas pode ajudar a explicar por que chegamos ao ponto de imaginarmos que gramados, árvores ornamentais, forraçōes anuais e lagos artificiais sejam a imagem da natureza, quando esta ainda aparece dentro da malha urbana.

De acordo com a visão comum, a natureza começa onde a cidade acaba, como se houvesse um limite intransponível entre a paisagem cultural e a natural, como entre as manchas pintadas de vermelho e de verde nos mapas, ou seja, entre o ambiente construído e a paisagem intocada: a cidade como inimiga da natureza...

Nesse discurso tradicional a ecologia é ligada à "natureza" das áreas protegidas e das espécies animais selvagens. Essa interpretação traz uma vantagem para um planejamento operacional: áreas naturais podem ser desapropriadas e cercadas e orçamentos para sua manutenção podem ser alocados. Espécies selvagens podem ser protegidas por medidas específicas, propostas por especialistas trabalhando em seus departamentos próprios. A divisão do trabalho é clara: cada setor da administração pública e do conhecimento técnico e científico estabelecido tem seus diferentes especialistas que defendem seus territórios. Assim, nesse contexto, a "natureza" é parte de um mundo separado espacial e funcionalmente.

Essa separação de funçōes, no entanto, não corresponde à realidade da interdependência existente entre os diversos elementos que compõem o ambiente: proteger "ilhas" de natureza em uma paisagem altamente transformada não é um enfoque sustentável, afinal não há cercas contra a poluição do ar ou dos lençóis freáticos, como alguns de inúmeros exemplos.

Gostemos ou não, a natureza ainda age no interior das cidades. A drenagem das águas das chuvas, a ilha de calor e o clima urbano, a estabilização dos solos, o subsolo que condiciona as fundações e demais estrututuras subterrâneas e o crescimento das árvores: todos esses processos estão atuando nas cidades; dessa forma, o seu planejamento deve necessariamente considerar esses processos biofísicos básicos que estão por trás do seu desenvolvimento.

Precisamos de uma estratégia para a reinserção desses processos que sustentam a paisagem local, que defina projetos sustentáveis para os espaços livres, a partir do relacionamento que estabelecem entre si, com sua inserção na cidade, e desta na região, que contribua ativamente para a imagem da cidade, que mude o modo mesmo como o ambiente urbano é percebido e usado. O planejador deve encontrar uma forma de permitir que a paisagem venha a participar para o auto-reconhecimento de seus usuários, e destes, para com o meio ambiente com o qual interagem, incorporando diretrizes ambientalmente desejáveis para a melhoria da habitabilidade da cidade, sua sustentabilidade e da significação de sua imagem. Um planejamento ecológico da paisagem pode fornecer as ferramentas para se alcançar uma integração plena entre sociedade e natureza, de forma que ambas prosperem a longo prazo. 


\section{Dimensão Projetual da paisagem: o Paisagismo}

O projeto de paisagismo situa-se sempre no limiar de conflitos. Conflito entre a cidade e o campo (entre meio urbano e meio rural), entre o solo e a água (entre meio sólido e meio líquido), entre o interior e o exterior dos edifícios (entre o "dentro" e o "fora" e também entre o público e o privadol, conflito entre o social e o natural. O que determina seu caráter sintético e formal (e estético). Considerando-se a forma como a coesão momentânea de conflitos entre conteúdos.

Isso implica em que o projeto paisagístico possa ser utilizado em vários momentos como instrumento fundamental para a definição de inter-relações tanto entre organismos e seus ambientes (como entre sociedades e seus territórios). Dependendo da estratégia adotada, ele pode tanto revelar a dialética entre processos naturais e sociais sobre o espaço, como, o que é mais usual, bloquear e destruir conexões entre comunidades e sítios.

Essa potencialidade inerente ao projeto de paisagismo começou a se evidenciar pela formulação do conceito de planejamento ecológico da paisagem, mesmo que a princípio de forma intuitiva, conseguiu uma visão que possibilitasse dirigir as mudanças na paisagem de maneira a estarem as ações humanas menos em conflito com os processos naturais.

Essa percepção já era encontrada no Brasil em meados do século 19, como no trabalho de recomposição da cobertura florestal do maciço da Tijuca, no Rio de Janeiro, então um importante manancial de águas para a cidade, ameaçado pela devastação das lavouras de café, em um trabalho iniciado pelo major Manuel Gomes Archer com o plantio, em 13 anos, de 100 mil mudas de árvores nativas, selecionadas e plantadas, reproduzindo uma mata heterogênea. Em continuidade, como intuito de embelezar e tornar a área atrativa ao lazer público, o barão de Escragnolle, com a colaboração do paisagista francês Glaziou, deram a feição final no que se constitui hoje o Parque Nacional da Floresta da Tijuca.

Posteriormente, nos EUA, Frederick L. Olmsted, considerado o fundador da profissão de arquiteto-paisagista, desenvolveu, em 1864, o plano para o Yosemite Valley, na Califórnia e, entre 1880 e 1890, o seu clássico plano para um sistema de parques metropolitanos ligando o Fens ao Parque Franklin, ao longo do Riverway em Boston, tendo como base características hidrológicas e ecológicas. Esses projetos representavam sua visão da paisagem como uma contínua interação entre sociedade e território, em contraste com o modelo de parque-jardim europeu continental, que redesenhava a "natureza" como um ideal de perfeição, a ser melhor observada de um ponto de vista exterior.

No século 20, as obras paisagísticas de Roberto Burle Marx também podem ser consideradas dentro da perspectiva americana, constituindo-se, além disso, em uma feliz combinação entre experiência científica e intenções plásticas na paisagem. De fato, desde o início de sua atuação já em 1934, em seus projetos de praças em Recife, que utilizam plantas oriundas da caatinga,

\begin{tabular}{|l|l|l|l|l|l|l|l|l|l|l|l|l} 
São Paulo n. 13 p. 159 & 179 & dez. 2000 & $\begin{array}{l}\text { Palsagem } \\
\text { Amblente } \\
\text { Ensalos } \\
13\end{array}$ \\
\hline
\end{tabular}


Paulo R. M. Pellegrino

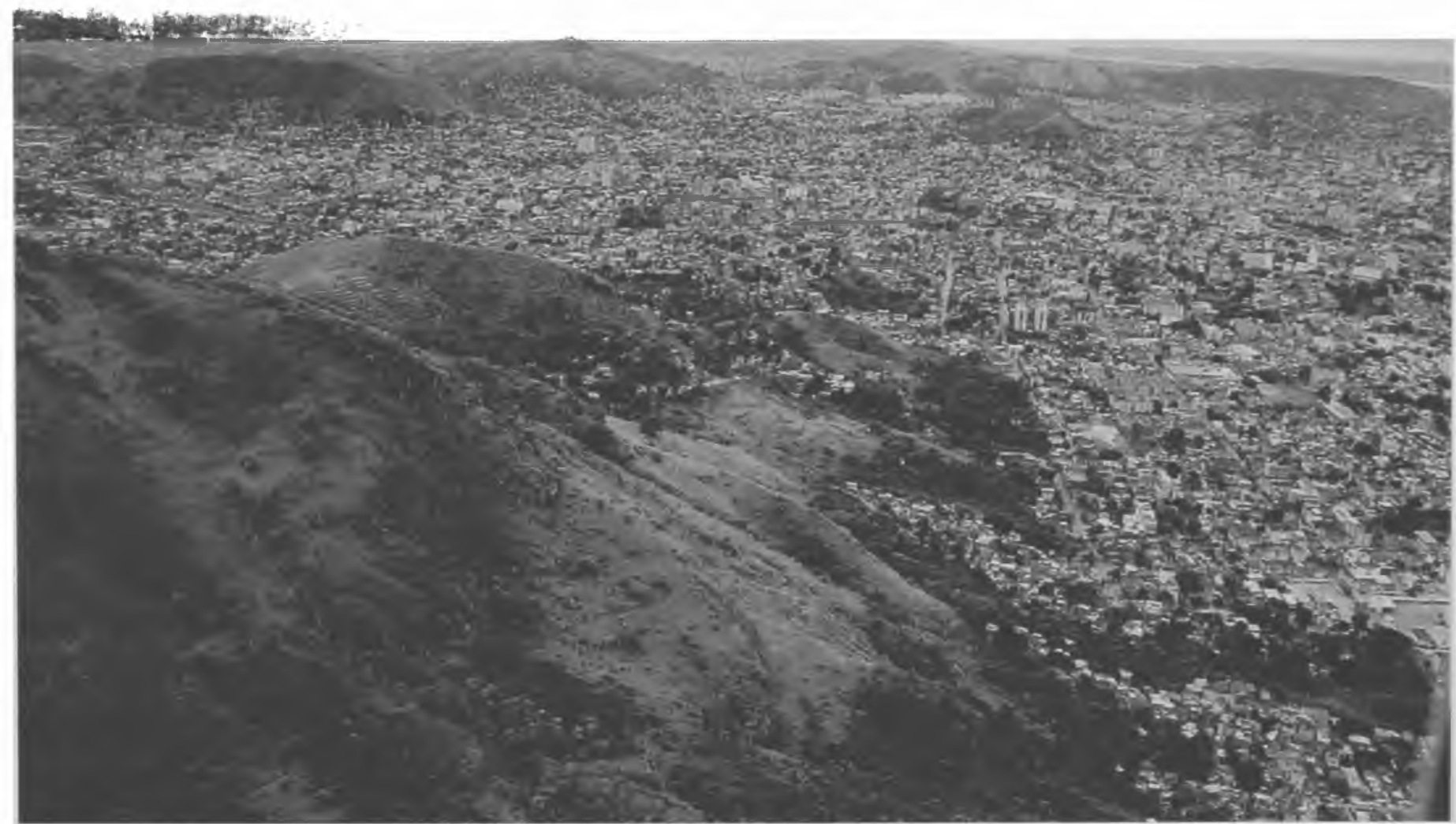

Foto 1: Morros do Mágico da Tijuca - na sua inferface com a zona norte

Fonte: Silvio Macedo

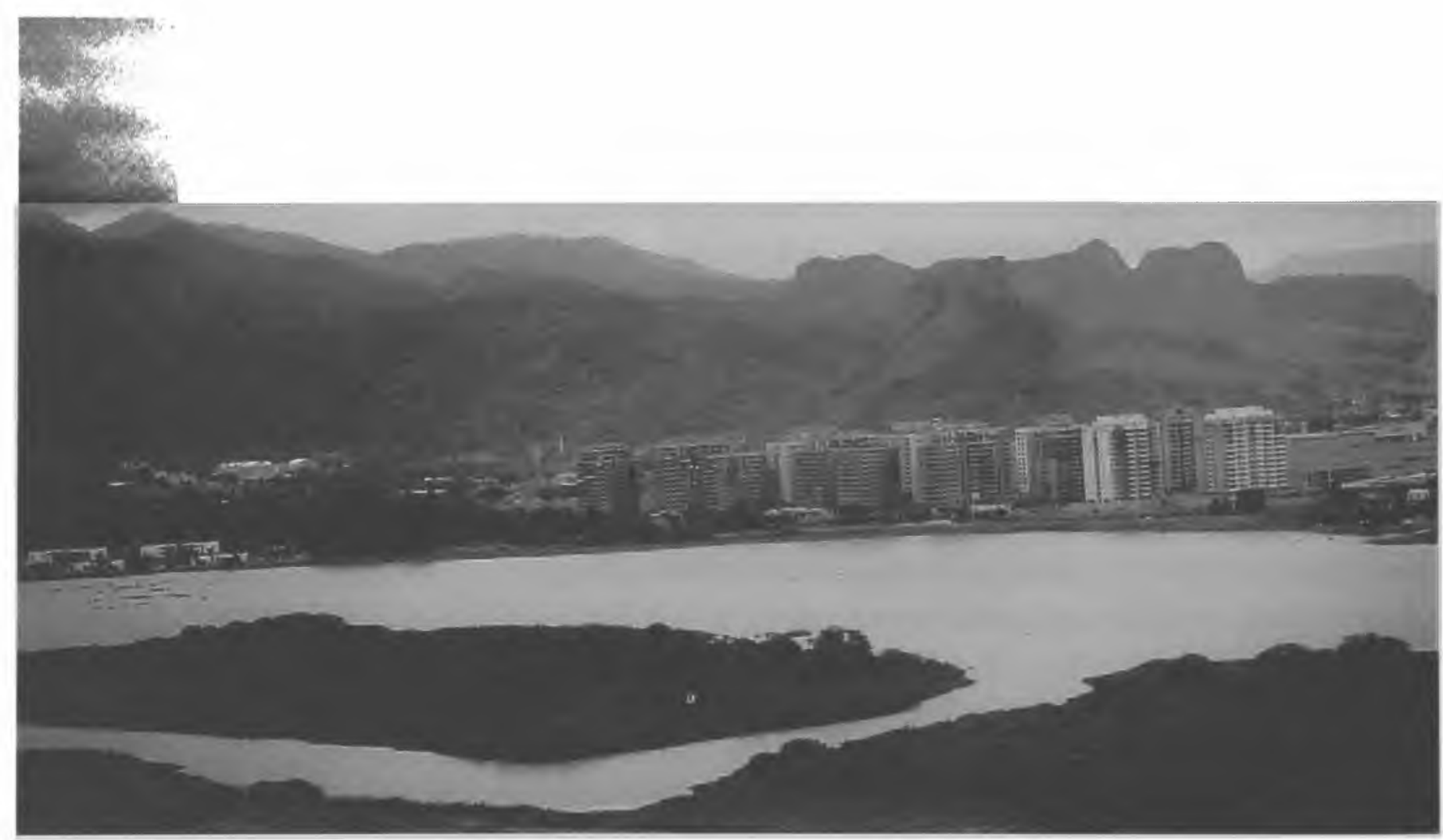

Foto 2: Vista da Serra da Tijuca

Fonte: Silvio Macedo

164 \begin{tabular}{l|llll} 
Paisagem & Ambiente \\
& Ensaios \\
13 & & &
\end{tabular}


como em 1943 no Parque do Araxá, no qual colaborou com o botânico Henrique de Mello Barreto, e também no Projeto do Parque Zoobotânico em Brasília, em 1961, e mesmo em sua obra mais famosa, o Parque do Flamengo no Rio, em meados da década de 60, há sempre o intuito de se evidenciar o significado científico (ecológico) e artístico com a utilização adequada da vegetação, a partir de sua relação com o contexto e das associações entre as espécies vegetais, observadas em seus ambientes originais.

Essa atitude abriu entre nós caminhos para uma nova visão da intervenção humana sobre a paisagem brasileira que não fosse apenas predatória, mas calcada em um profundo conhecimento das leis da natureza. Essa postura permitiria que à medida que se avançasse o desenvolvimento territorial da sociedade nos trópicos, também fosse ampliado o conhecimento sobre a flora, a fauna e o ambiente, criando-se um novo conhecimento e uma nova ética na paisagem.

Durante o New Deal, nos EUA, discute-se a definição de região: se esta se baseia nos aspectos biofísicos ou em seus condicionantes socioculturais, ou em ambos. Este debate influencia Lewis Munford e Howard Odum, o qual, com Rexford Tugwell, planejam as comunidades greenbelt. Nas décadas de 30 e 40, o Soil Conservation Service (SCS) cria diretrizes para o uso adequado do solo pelo desenvolvimento de mapas de capacidade de uso do solo (land capability maps), desenhados para determinar a vocação agrícola de uma área. Trabalhando no SCS, o biólogo e engenheiro florestal, Aldo Leopold, inicia o planejamento de áreas de mananciais, propondo considerar de maneira integrada o solo, a água, as plantas, os animais e a população concernida. Segundo esse autor, dessa nova postura ética se derivaria uma nova estética da terra. A Tennessee Valley Authority (TVA), estabelecida em 1933, demonstrou a eficácia da utilização de uma bacia hidrográfica como uma unidade de planejamento territorial e paisagístico, ao promover o controle das enchentes, a produção de energia e o desenvolvimento do comércio e da navegação fluviais. Estas três experiências - e é interessante notar que surgem em uma época de depressão econômica profunda - serviram para consolidar os paradigmas do planejamento da paisagem em um esforço para se alcançar um balanço sustentável entre a acomodação de necessidades sociais e a proteção dos recursos culturais e naturais significativos.

Mas um consenso só seria alcançado nos anos 60 com o trabalho, entre outros, de Philip Lewis e lan McHarg. Lewis, preocupado com aspectos perceptivos - vegetação e paisagens notáveis -, encontrou nos cursos d'água, áreas alagadas e na topografia, recursos perceptivos únicos que quando interligados formavam um padrão linear, denominados de greenways; tal padrão pode relacionar qualidades visuais da paisagem com aspectos ambientais naturais.

lan McHarg, com o emprego de princípios da ecologia como a base de reconciliação entre sociedade e seu suporte biofísico, desenvolve o método conhecido como suitability analysis, que constava da superposição de uma série de mapas temáticos transparentes (overlays), que interpretados como processos e valores, revelam áreas apropriadas aos diferentes usos humanos, o que foi exposto em seu livro Design with nature, de 1969. 
Com a aplicação da tecnologia dos computadores no planejamento da paisagem e com a criação de nova legislação ambiental de prevenção e recuperação de impactos ambientais, abre-se para o arquiteto-paisagista a possibilidade de avaliar e atuar em escalas maiores os recursos naturais, visuais e culturais das paisagens. Sopreposiçōes de mapas, como de solos, vegetação, densidade habitacional, planícies aluviais, hipsometria, áreas de preservação, indústrias, etc., já têm sido utilizadas há longo tempo para identificar localizações apropriadas e inapropriadas para futuros usos do solo. lan McHarg (1969) enfatizou esse procedimento para conectar as dimensões ambientais e projetuais da paisagem. A disponibilidade de sistemas de informações geográficas, hoje, faz deste procedimento de combinar características existentes em cada ponto georreferenciado, permitindo sua comparação direta, uma atividade rotineira. Esse método, entretanto, não basta para compreender satisfatoriamente a multiplicidade de interaçōes entre sociedade e paisagem, já que os diversos elementos (como solo e vegetação) são apresentados como realidades independentes e distintas dos usos sociais do território, há ainda relações relevantes não passíveis de representação gráfica (ou quantificáveis) como as definidoras do caráter dinâmico e histórico da paisagem.

Mas McHarg projeta ainda uma nova cidade - Woodlands, Texas - que se torna um exemplo bem-sucedido de utilização do método de suitability analysis e de manejo de informações ecológicas para desenvolver um plano geral com critérios para implantação, calcados no "balanço natural do regime hidrológico como a peça-chave para um planejamento ambiental bem-sucedido e um conceito orientador para o desenvolvimento" (McHarg, 1975).

Eugene Odum, um ecologista da Universidade da Georgia, estabeleceu um esquema conceitual de como os ecossistemas mudam de acordo com as intervenções humanas, clarificando as relações existentes entre os tipos de paisagens requisitadas pelas atividades humanas e as funçōes ecológicas de suporte necessárias. Seu modelo dividia as paisagens de acordo com suas quatro funçōes ecológicas básicas: produção (agricultura, reflorestamento); proteção (áreas alagadas, florestas nativas); de compromisso ou múltiplos usos (chácaras de lazer, parque recreativos) e biologicamente não-vitais (áreas urbanas e industriais), oferecendo uma base teórica para um planejamento regional integral.

Na primeira tendência, retirava-se a ênfase dada aos aspectos naturais, tentando-se avançar na compreensão da interação entre os processos naturais e sociais, introduzindo o estudo de características culturais da população, além da mera quantificação de dados socioeconômicos e demográficos. Essa abordagem qualitativa procura um entendimento sobre a evolução do conhecimento acumulado pelas pessoas sobre um determinado lugar, sobre como as pessoas afetam e são afetadas pelo ambiente (percepção ambiental), integrando valores sociais e culturais ao planejamento da paisagem.

No final do anos 70, como a mentalidade de proteção ambiental já está consolidada, os princípios ecológicos do planejamento se voltam à paisagem urbana, considerada como parte integrante da natureza. Dessa forma, nos trabalhos de Michael Hough, Anne Spirn e 
John Lyle, processos semelhantes aos que ocorriam em áreas rurais passam a ser reconhecidos e analisados cuidadosamente nos ambientes construídos. Por exemplo, os sistemas de drenagem nas cidades freqüentemente acabavam interrompendo e mesmo destruindo o ritmo natural de movimento das águas, ao invés de tirar proveito desse potencial. Esses autores concordavam ser essencial considerar as paisagens urbanas como ecossistemas, ou seja, como uma coleção de organismos interagindo uns com os outros e com os ambientes natural e construído. O ponto de partida proposto por eles era entender os mecanismos subjacentes aos ecossistemas urbanos (e suas expressões visuais), como base para projetos que garantissem sua sustentação.

A ecologia da paisagem surge entāo como tentativa de traduzir princípios ecológicos para a escala prática dos planejadores e arquitetos, visto que a maioria dos ecologistas não pensam visualmente, fazendo com que a informação ecológica seja dificilmente organizada de forma a ser imediatamente útil à intervenção. Forman e Godron, em sua obra de 1986, Landscape ecology, fundiram o conhecimento de geógrafos, ecologistas, arquitetos-paisagistas, planejadores e historiadores para entender a estrutura, função e mudança das paisagens, criando um quadro de referência pelo qual os arquitetos e planejadores podem explorar como a configuraçāo paisagística do território evolui junto com os processos ecológicos mais relevantes, como um mosaico interagente de ecossistemas, conectados por fluxos de energia e matéria.

\section{- Planejamento Ecológico da Paisagem}

Planejamento ambiental e/ou paisagístico tem significados diferentes para diferentes pessoas, portanto torna-se necessária uma clarificação da expressão.

A programação do uso dos recursos pela sociedade, integrando conhecimento técnico e científico que forneçam opçōes para a tomada de decisōes sobre alternativas futuras, é planejamento.

Paisagem aqui denotará a escala perceptível entre os processos humanos e os naturais.

A combinação dos aspectos naturais e culturais que criam a paisagem incluem elementos visíveis como campos, matas, lagos, rios e cidades. Por sua vez, a maneira pela qual estes elementos são utilizados reflete a cultura de seus habitantes e, por extensão, a atividade de planejamento da paisagem, baseada em princípios conservacionistas, implica a tomada de decisōes sobre alternativas de redesenho paisagístico, centradas no uso racional e sustentado dos recursos ambientais na acomodação das necessidades e interesses humanos.

Uso racional e sustentado da paisagem significa, portanto, o melhor uso considerando-se todos os aspectos que condicionam a conservação dos recursos, ou seja, reconhecer a necessidade de proteção dos recursos naturais e culturais de forma que o atendimento dos

\begin{tabular}{|lll|}
\hline São Paulo n. 13 p. 159 & 179 dez. 2000 & $\begin{array}{l}\text { Paisagem } \\
\text { Ambiente } \\
\text { Ensaios } \\
13\end{array}$ \\
\hline
\end{tabular}


interesses do presente não comprometa a capacidade das futuras gerações de atenderem às suas necessidades.

As paisagens mudam por processos naturais ou pela ação das pessoas. Essas mudanças podem levar a uma maior estabilidade ou não dos ecossistemas.

O planejamento ecológico da paisagem é a criação de uma solução espacial capaz de manejar as mudanças dos elementos da paisagem, de forma que as intervençōes humanas sejam compatibilizadas com a capacidade dos ecossistemas de absorverem os impactos advindos das atividades previstas e de se manter a integridade maior possível dos processos e ciclos vitais que ocorrem em seu interior, sempre tendo-se como referência o contexto regional do qual fazem parte.

\section{A Ecologia da paisagem Aplicada ao Planejamento da Paisagem}

A ecologia da paisagem oferece um conjunto de princípios capazes de serem aplicados ao projeto e ao planejamento das paisagens e regióes, tendo emergido na última década como uma ferramenta importante para os planejadores e para os arquitetos-paisagistas manusearem informações coletadas sobre uma determinada área, analisá-las, interpretá-las e de realizarem proposições na escala da paisagem urbana e regional. Respondendo, assim, ao desafio de criação de um modelo que é uma linguagem espacial a permitir a comunicação entre as diversas disciplinas e os tomadores de decisões.

Para o entendimento das relações que os diversos elementos do mosaico de paisagens estabelecem entre si, a ecologia da paisagem estabelece um conjunto básico de princípios que podem ser assim sumarizados:

Os princípios da ecologia da paisagem aplicam-se a qualquer mosaico paisagístico: desde as áreas urbanas às agrícolas, aos desertos e às florestas. Eles se aplicam tanto às áreas naturais quanto às de intensa atividade humana.

Como um sistema que contém seres vivos em abundância e evolui, apresenta três características principais: estrututra, função e mudança.

Estrutura da paisagem é o padrão espacial ou o arranjo dos elementos paisagísticos.

Função é o movimento e o fluxo de pessoas, animais, plantas, água, vento, matéria e energia, pela estrutura.

Mudança é a dinâmica ou alteração no padrão espacial e na função através do tempo.

O padrão estrutural de uma paisagem ou região é composto inteiramente de três tipos de elementos: manchas, corredores e matriz, que servem tanto para comparar paisagens alta- 
mente dissimilares como para desenvolver os princípios gerais. Eles também servem para o planejamento do uso do solo e para a arquitetura paisagística, já que o padrão espacial controla fortemente os movimentos, fluxos e mudanças.

A concisão desta linguagem espacial torna-se evidente ao considerarmos que toda a variedade de mosaicos paisagísticos existentes sobre a superfície da Terra é resultante da combinação entre matriz, corredores e manchas.

Toda a variedade encontrada na distribuição dos elementos que compõem as paisagens é conseqüência da heterogeneidade do substrato, de alterações naturais e da atividade humana.

Processos naturais, tanto quanto as atividades humanas, mudam as paisagens e muitos processos espaciais tornam-se evidentes numa avaliação temporal, tais como fragmentação, perfuração, dissecação, diminuição, atrito e coalescência.

Cada um desses processos espaciais apresentam diversas implicações humanas e ecológicas, como a biodiversidade e a efetivação dos ciclos naturais.

Tendo esses processos espaciais como referência, os atributos-chave de cada um dos elementos da paisagem podem ser avaliados:

- As manchas são grandes ou pequenas? Redondas ou alongadas? Lisas ou recortadas? Poucas ou numerosas? Isoladas ou agrupadas? Etc.

- Os corredores são largos ou estreitos? Retos ou curvilíneos? Contínuos ou desconectados? Etc.

- A matriz é única ou subdividida? Variegada ou homogênea? Contínua ou perfurada? Etc.

Por exemplo, na escala local, a mudança na configuração de um mosaico com a introdução de um renque de árvores, a criação de um açude, uma estrada e edificações, muda o seu funcionamento: animais alteram sua rota, o fluxo das águas é redirecionado, a erosão do solo se modifica, as pessoas passam a se mover diferentemente. E estas transformações causam ainda mudanças maiores nas áreas adjacentes.

Manter, remover ou introduzir elementos na paisagem é a forma de manejamento que os planejadores e os arquitetos-paisagistas têm para mudar a estrutura e funcionamento do mosaico de paisagens.

A previsão e avaliação dos impactos a serem causados pelos rearranjos dos elementos que compõem a paisagem permite a implantação de políticas de uso e ocupação do solo, as quais, reduzindo a fragmentação e degradação de seus elementos, assegurem certa estabilidade a longo prazo. 

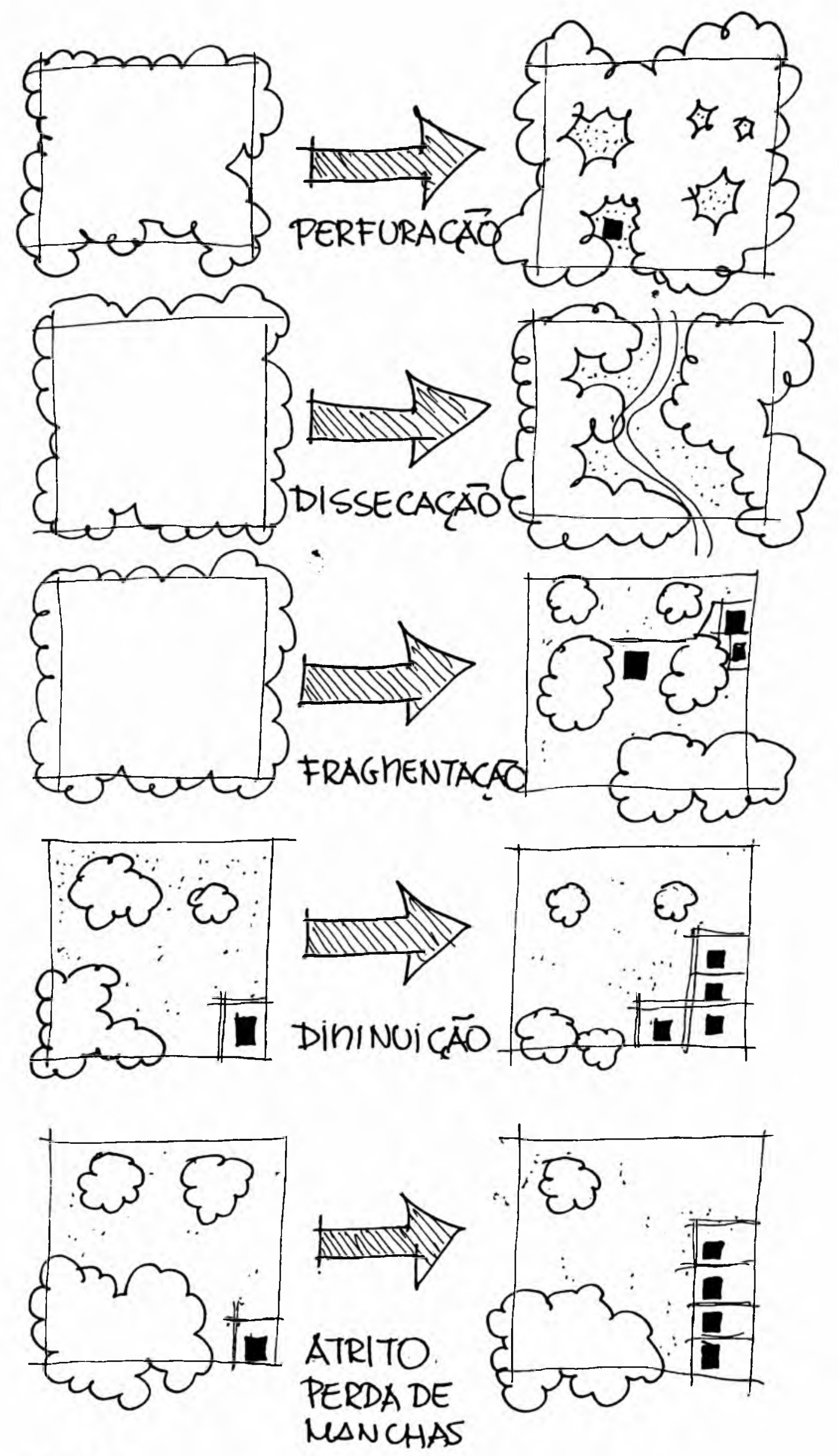

Figura 4

Fonte: Silvio Macedo 

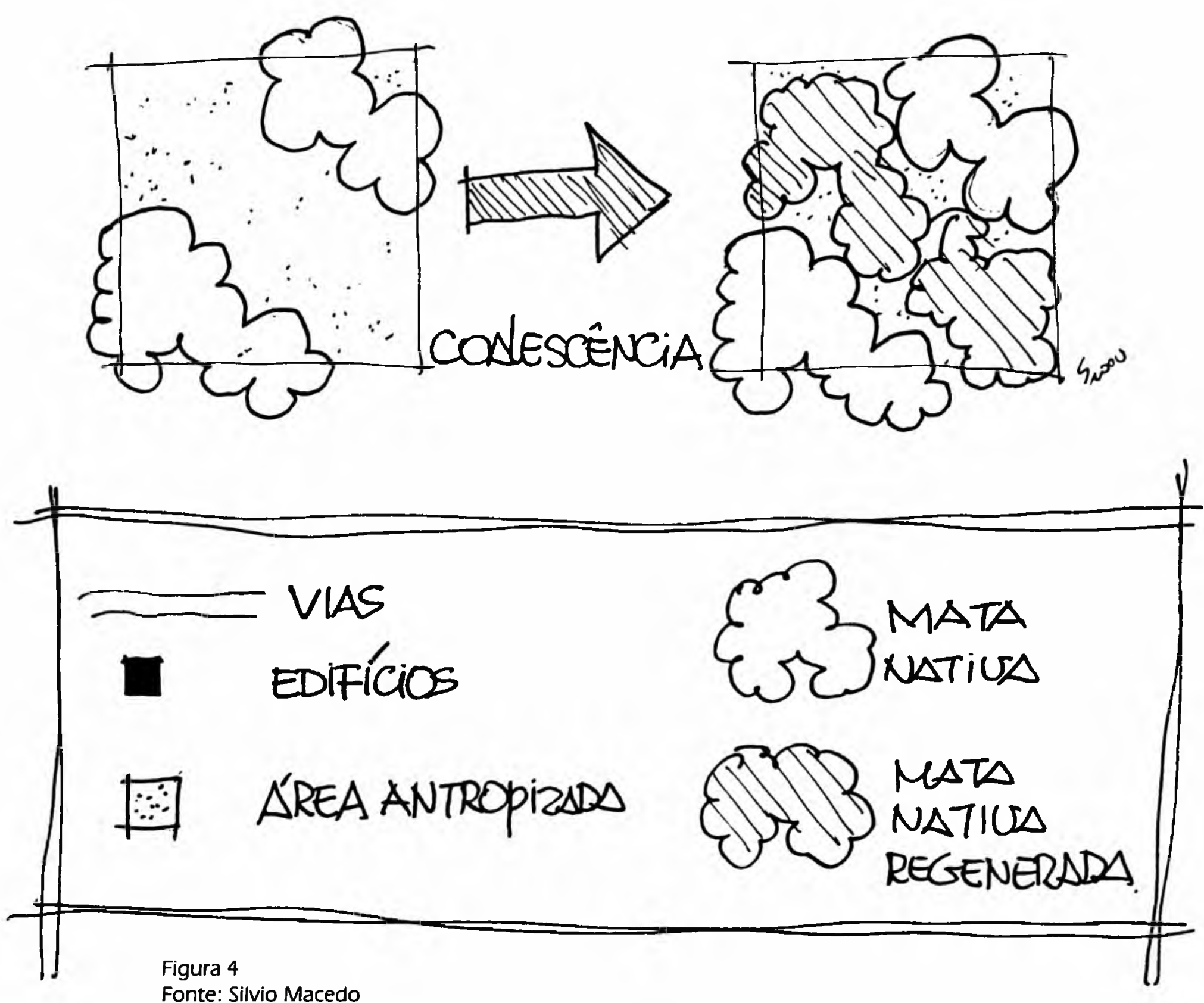

Visando a criação de ambientes sustentáveis, a estratégia básica para tanto deve procurar que as configurações previstas no mosaico de paisagens atendam aos princípios de: concentração, conexão e conservação.

\section{- Processo de Planejamento da Paisagem}

Os desafios constantes no planejamento, projeto e manejo de uma área não se resumem em se ter uma visão espacial e temporal ampla de uma área, mas em se enfrentar as principais questões sociais e ambientais presentes. Abastecimento de água, transporte e circulação, biodiversidade, recursos paisagísticos, relações culturais e comunitárias, agricultura entre outros tantos mais, são fatores essenciais a serem considerados. Para que todos os planos atendam adequadamente a essas questões, uma ampla gama de conhecimentos técnicos específicos deve ser alcançada. 
Como prática corrente no desenvolvimento de um plano para uma área, há o trabalho de um especialista ou de grupo de especialistas, com um determinado enfoque visando um objetivo principal. Apoiando-se nos princípios da ecologia da paisagem, pode-se, ao contrário, integrar esquematicamente todas as dimensões na paisagem que são espacialmente explícitas, como a cultural, estética e socioeconômica com a dimensão ambiental.

No entanto, nenhuma revisão geral é ainda disponível da aplicação dos princípios da ecologia da paisagem no planejamento, conservação, projeto e manejo. Mas esses princípios oferecem uma teoria e uma evidência empírica para o entendimento e comparação entre diferentes configurações espaciais, que nos permite enfrentar a questão central: qual é o arranjo ótimo do uso do solo numa paisagem?

A partir do quadro de referência dado pelos princípios da ecologia da paisagem, sabemos que a solução espacial deve, segundo Forman (1997), contemplar no seu delineamento três aspectos:

\section{Quatro padrões indispensãveis}

Os componentes de máxima prioridade num plano, de acordo com benefícios ecológicos que produzem são:

1) A manutenção de algumas grandes manchas de vegetação

Alguns dos benefícios que oferecem são: proteção da qualidade da água de aqüíferos e corpos d'água; conexão da rede inferior de cursos d'água; hábitat para espécies de interior de manchas; hábitat-núcleo e refúgio para espécies que precisam de grande território, fonte de dispersão de espécies; proximidade de microhábitats para espécies multihábitat; regime de alteração próximo ao natural; zona-tampão contra extinção durante mudança ambiental.

Grandes manchas: grandes benefícios; pequenas manchas: pequenos benefícios suplementares.

Como hipótese temos: uma paisagem "ótima" possui grandes manchas, suplementadas por pequenas manchas distribuídas pela matriz.

Não importa qual seja a política de uso do solo, quase todas as paisagens deverão ter pequenas manchas. E manter os benefícios sociais das grandes manchas de vegetação requer medidas efetivas de planejamento e proteção.

Não existe um tamanho ótimo, um mínimo ou um máximo para as manchas. Existem limiares sobre os quais basearemos nossas decisões, mas isso permanece indefinido. Respostas podem depender, se uma grande mancha é comparada com uma ou diversas manchas pequenas em relação a efeitos ecológicos como a biodiversidade, produtividade da biomassa, erosão, recarga do ciclo hidrológico, etc.

2) Corredores suficientemente largos de vegetação ao longo dos principais cursos d'água 


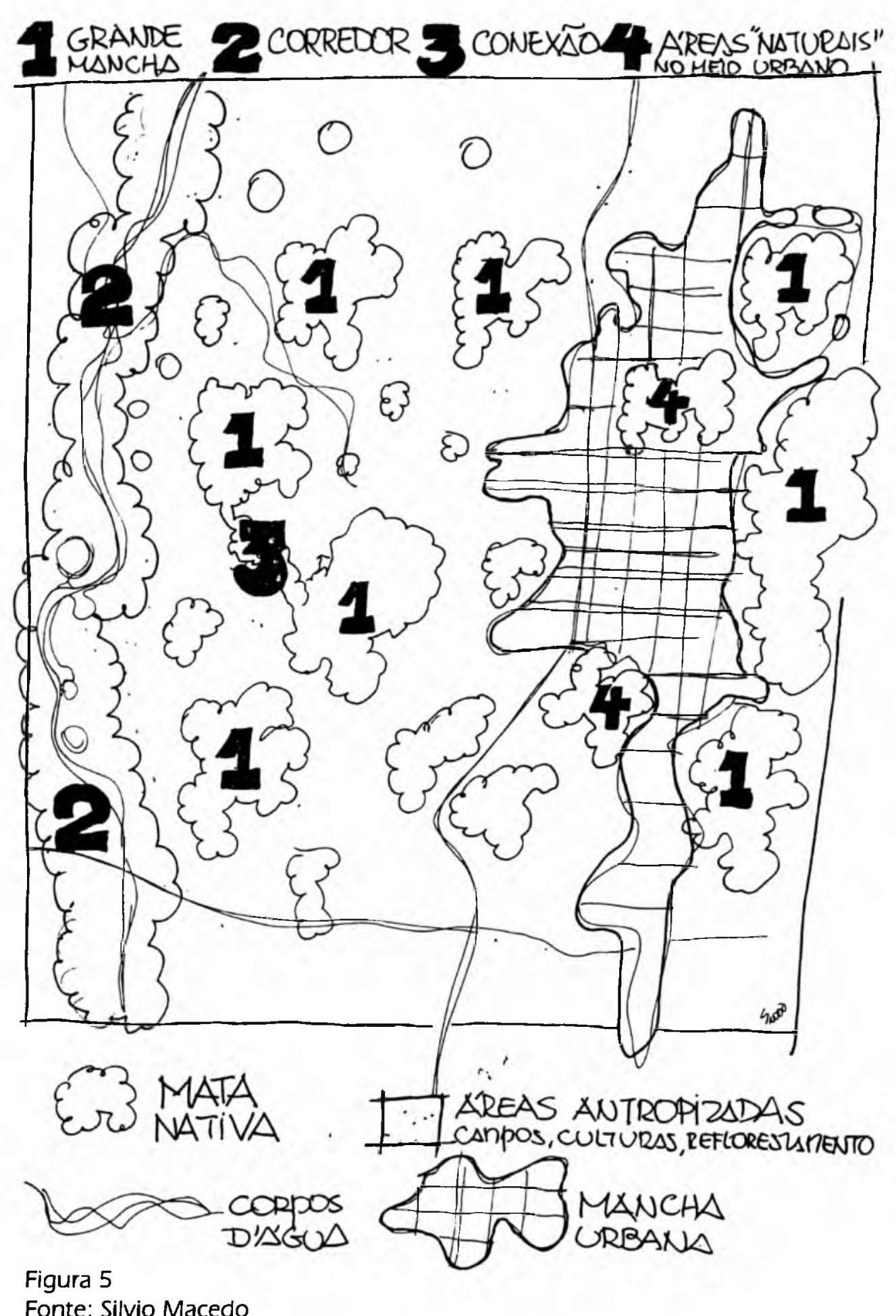

Fonte: Silvio Macedo

Quase todos os recursos naturais e as atividades humanas numa paisagem dependem dos rios e sistema de drenagem das águas superficiais existentes.

Um corredor ao longo de um rio é a faixa de vegetação que acompanha a superfície de água corrente. O corredor pode apenas incluir esta superfície de água e suas margens adjacentes, ou pode ser largo o suficiente para incluir a planície aluvial, suas encostas e faixas de terras altas limítrofes. Vegetação ciliar, geralmente refere-se à vegetaçāo da planície aluvial ou da área de inundação direta de um rio. 
A vegetação ao longo de um rio atende a quatro importantes funções ecológicas: (a) minimização das enchentes a jusante através da friç̧ão, efeito esponja e aitas taxas de evapotranspiração; (b) controle do assoreamento por reter sedimentos; (c) fonte de matéria orgânica para peixes e demais organismos fluviais; e (d) hábitats para muitas espécies significativas.

Qual deve ser a largura de um corredor ao longo de um rio? Este é provavelmente o problema mais freqüente para os planejadores. Três passos podem levar a uma solução: (a) delinear os processos ou funções ecológicas-chave desempenhadas pelo corredor; (b) separar os tipos básicos de cursos d'água desde as cabeceiras até a foz, baseando-se na estrutura espacial existente no corredor; e (c) determinar a largura requerida por cada tipo de curso d'água, cruzando os processos ecológicos mais sensíveis com a estrutura espacial.

Um corredor deve ser contínuo? O efeito do tamanho da interrupção num corredor depende da combinação entre os componentes espaciais do relevo e os processos ecológicos mais sensiveis presentes, aplicada à zona climática em que se insere.

3) Manutenção de conectividade entre grandes manchas para o movimento de espécies-chave

Corredores contínuos suficientemente largos, formando uma rede principal de corredores verdes, são considerados o melhor mecanismo para a movimentação de eśpécies entre as manchas maiores.

A segunda melhor alternativa é um conjunto de manchas menores de apoio, desde que a matriz intermediária não seja completamente inapropriada para o movimento das espécies.

Qual é sua melhor localização e configuração? Dependendo de suas características - contínuos, formados por conjuntos ou linhas de manchas, em gradiente ou seccionados por barreira - podem ter uma conectividade alta, baixa, média ou desprezível.

Corredores verdes junto às áreas urbanas também desempenham função recreacional e estética.

4) Manutenção de trechos naturais heterogêneos no meio das áreas construídas

Esse recurso possibilita a manutenção de certa conectividade para o movimento de grande parte das espécies por todas as porções da paisagem. Também interrompe áreas extensivas de uma matriz, sujeitas a erosão eólica, ilha de calor, etc.

Esse componente é alcançado efetivamente com a montagem de pequenas manchas heterogêneas de vegetação nativa e de uma rede de corredores lineares.

Essa heterogeneidade de situações deve incluir espécies e hábitats dispersos por toda a matriz. Enquanto grandes áreas protegem muitas espécies e situações significativas, outras espécies e situações dependem do manejo do uso do solo nas imediaçōes.

$174 \begin{aligned} & \text { Paisagem } \\ & \text { Ambiente }\end{aligned}$ Ensalos 13 


\section{- modelo "agregados com áreas externas" (aggregate with outliers)}

Aparece como uma maneira eficaz de harmonizar diferentes usos do solo.

Qual é a melhor distribuição dos usos do solo numa paisagem? Para responder esta questão, esse modelo, que não procura descrever a complexidade de qualquer paisagem real, determina que se deve procurar agregar usos do solo, ao mesmo tempo mantendo corredores e pequenas manchas naturais nas áreas construídas, bem como trechos construídos, distribuídos, ao longo dos limites principais das manchas e corredores naturais.

Sete dos principais atributos ecológicos da paisagem são incorporados ou solucionados por este modelo:

1) manchas grandes de vegetação nativa, como já colocado;

2) granulação - a granulação de um mosaico de paisagens significa o diâmetro ou área média de todas as manchas numa paisagem e afeta muitos fatores ecológicos, dependendo de sua granulação ser grossa ou fina;

3) redução de risco - evita que todos os indivíduos de uma espécie estejam numa única mancha, o que aumentaria o risco de sua perda;

4) variação genética - diversidade genética é importante por prover defesa às alterações ambientais;

5) zonas de contato - as áreas entre os usos de solo, incluindo as bordas das maiores manchas adjacentes, sāo freqüentemente adequadas para trechos construídos, já que nessas áreas estes não perfuram excessivamente e destroem as vantagens das grandes manchas. A curvilinearidade dos limites reduz o efeito barreira aparente dos limites retilíneos e reproduzem melhor os efeitos dos processos naturais;

6) pequenas manchas de vegetação nativa, como já colocado;

7) corredores - além dos naturais, já descritos, corredores compostos por diversos usos do solo resultam numa circulação humana mais eficiente entre os diversos usos do solo, concentrando o movimento e desta forma minimizando os movimentos indesejáveis pelas grandes manchas.

Além desses benefícios ecológicos, este modelo traz benefícios diretos no desenho dos assentamentos humanos:

(1) abre uma ampla gama de situações possíveis;

(2) indica locações adequadas para edificações rurais e casas de campo;

(3) concentra áreas para trabalho, moradia, serviços e comércio; 


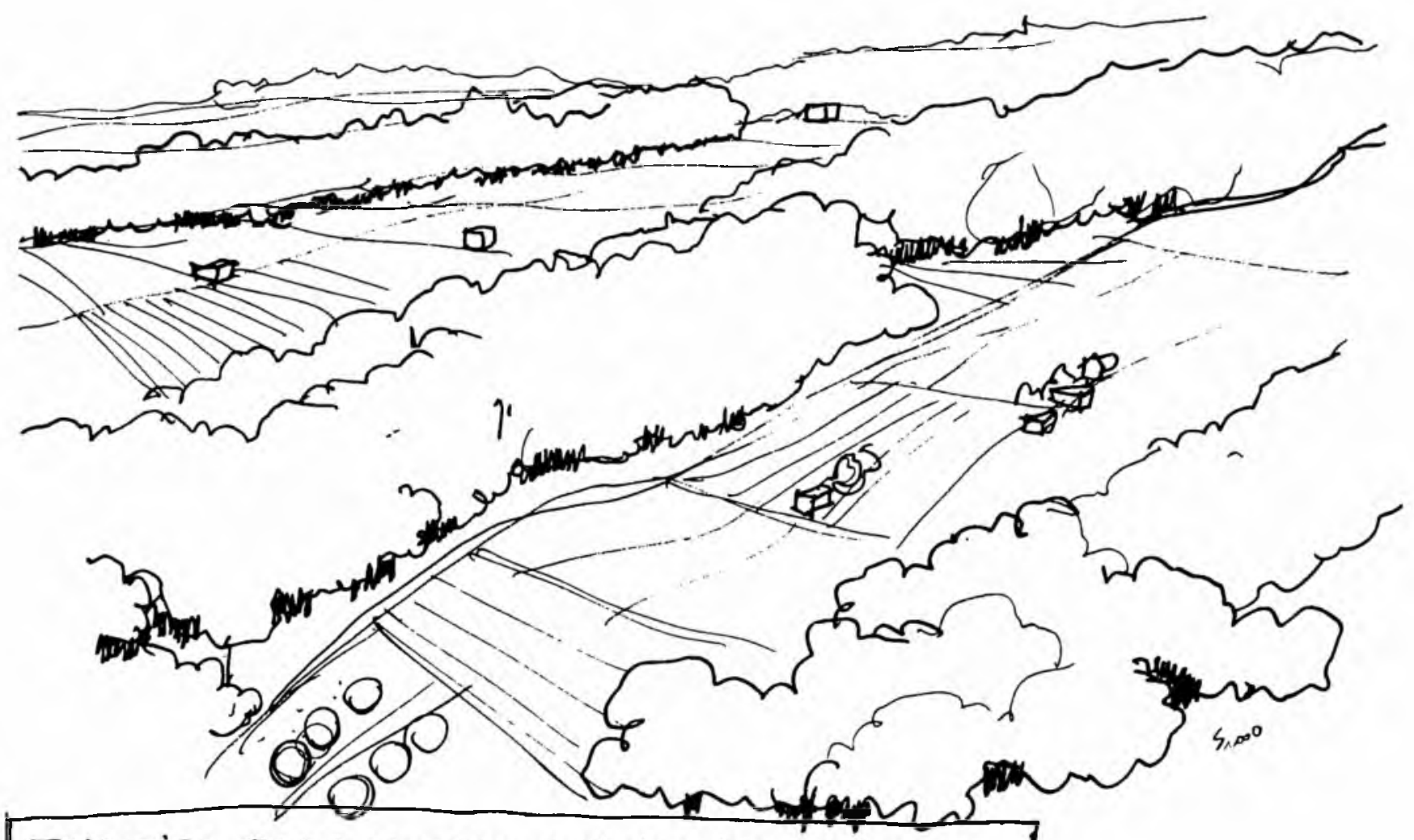

PRIMEIRA fase-campos culTivados e mazas
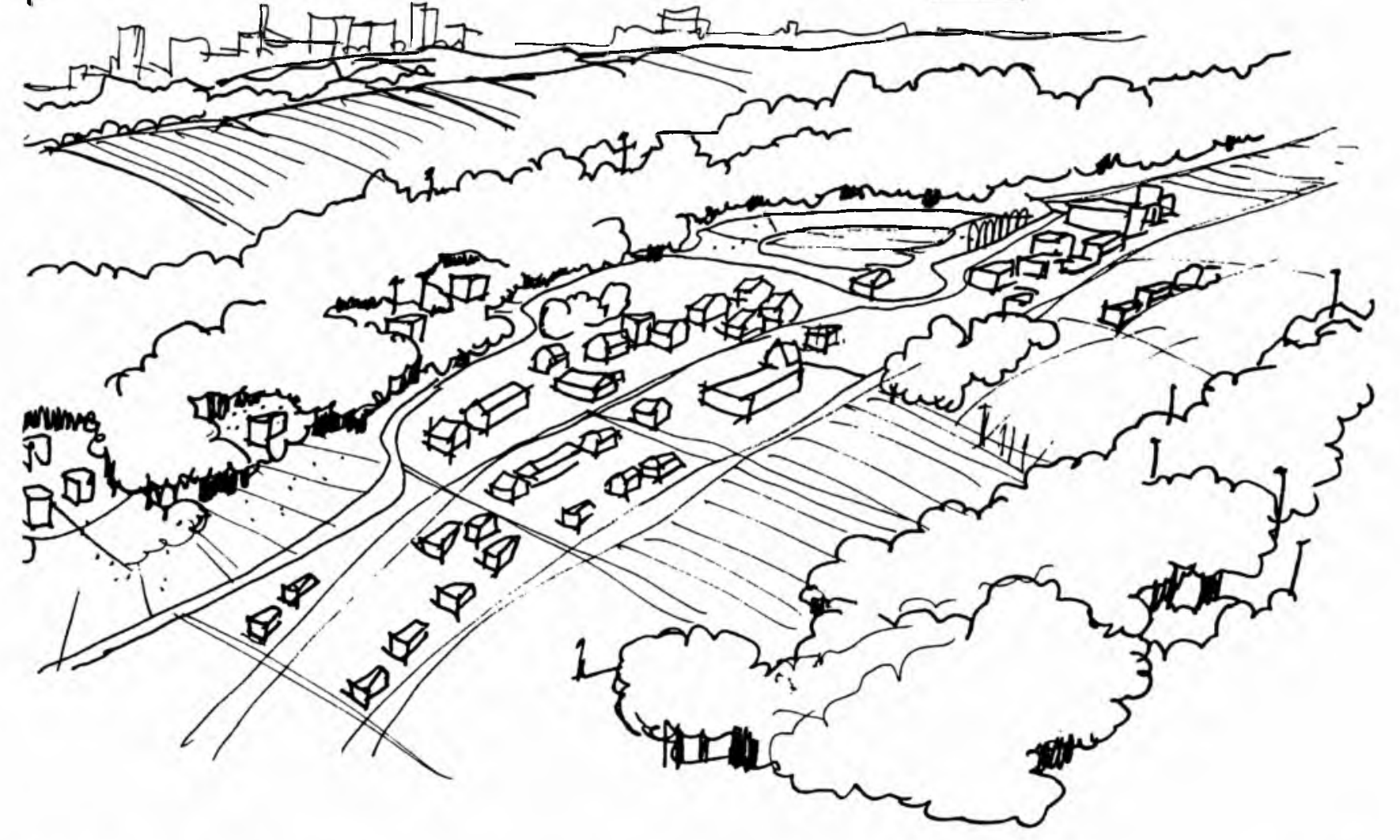

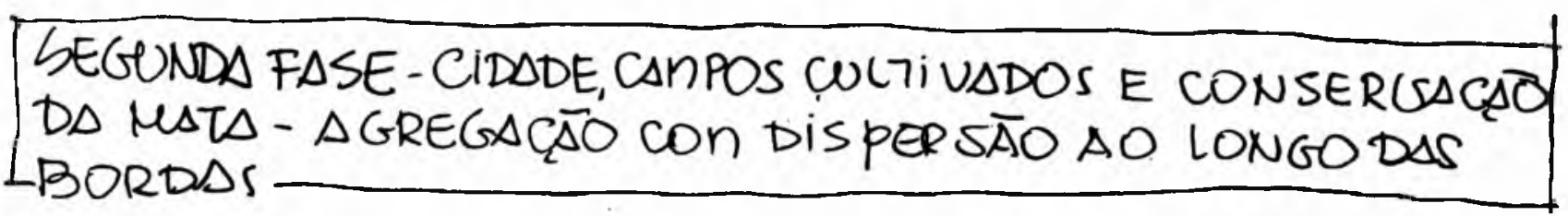

Figura 6

Fonte: Silvio Macedo 
(4) torna mais eficiente a circulação e o transporte entre zonas e cidades ao longo de corredores;

(5) impede conurbaçōes e valoriza a identidade local com vegetação nativa e agricultura atravessando corredores;

(6) agrega áreas construídas especializadas;

(7) cria espaços livres verdes urbanos;

(8) prevê grandes manchas para uma extração eficiente de recursos;

(9) limita as dificuldades decorrentes do isolamento de propriedades rurais;

(10) provê diversidade visual pela variação na granulação.

\section{Pontos estratégicos}

Localizações excepcionais de significado duradouro numa paisagem

Com a estrutura espacial para toda a paisagem estabelecida, localizações estratégicas em seu interior podem ser estabelecidas a partir dos seguintes critérios:

1) aspectos únicos - tendem a ser "entradas e saídas" especialmente importantes;

2) proteger elementos com a mais alta riqueza de espécies - é eficiente para a conservação da biodiversidade na paisagem;

3) grandes nós em redes - têm importância especial por causa das ramificações de suas conexões;

4) interrupçōes (gaps) nos principais corredores - são chave para o movimento ao longo e fluxos através de um corredor;

5) centro de fluxos similares - são críticos porque fluxos e movimentos neles afetam muitos outros elementos na paisagem;

6) proteger elementos com alta sensibilidade aos impactos humanos - provê importante estabilidade à paisagem;

7) focar nos pontos estratégicos - permite um importante controle, pouco comum, sobre os fluxos (o funcionamento da paisagem), bem como proteção às forças externas.

Talvez, nem todas essas soluções espaciais sejam indispensáveis para a conservação e o manejo, mas todas têm um amplo impacto sobre a paisagem pelos seus fluxos e movimentos. Dessa forma são oportunidades excepcionais e instrumentos à mão para o planejador. 


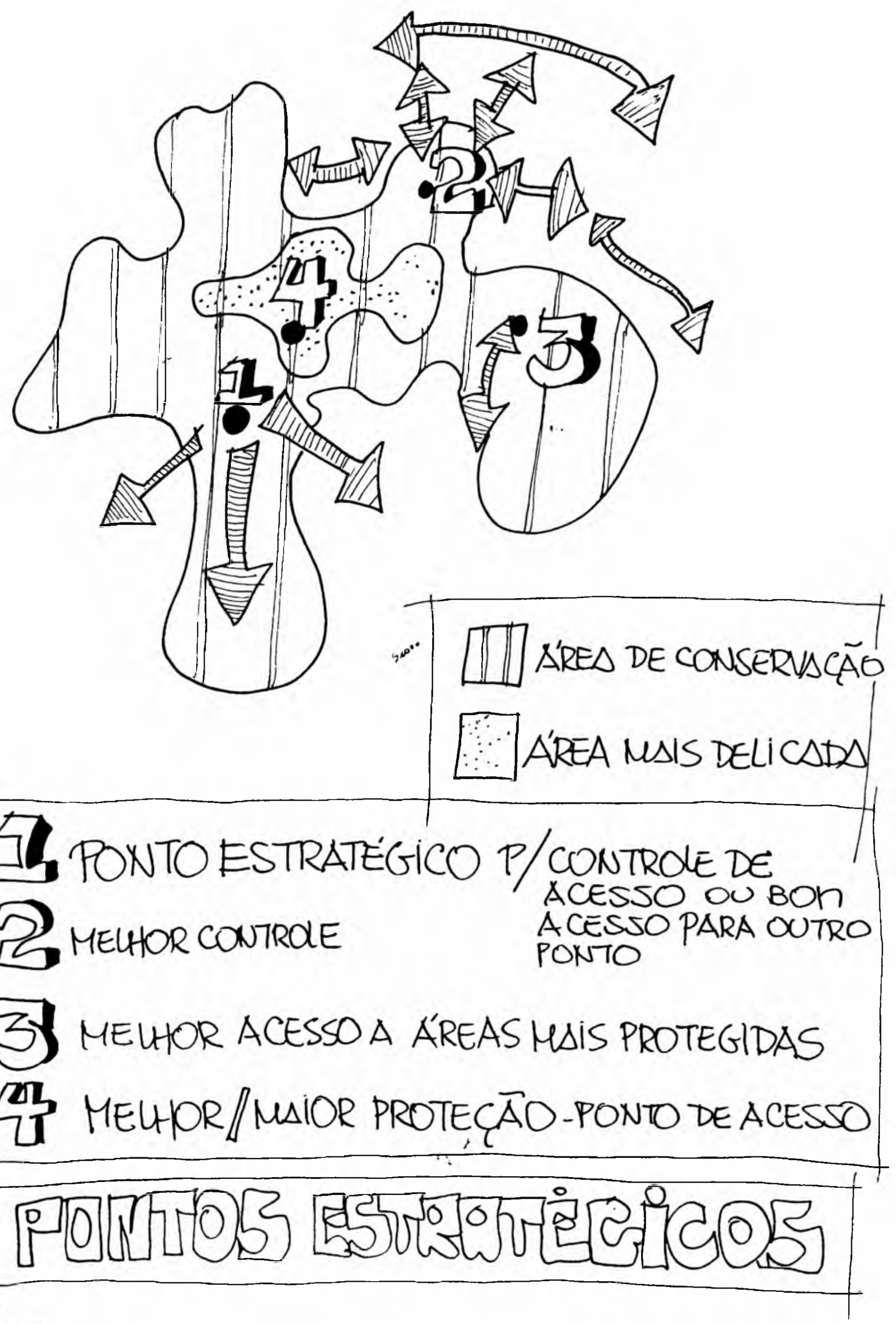

Figura 7

Fonte: Silvio Macedo 


\section{Bibliografia}

ARENDT, Randall G. Conservation design for subdivisions: A practical guide to creating open space networks. Washington: Island Press, 1996.

ARENDT, Randall G. et al. Dealing with change in the Connecticut River Valley: A design manual for conservation and development. Cambridge, Mass.: Lincoln Institute of Land Policy, 1989.

CASTRO MAYA, Raimundo Ottoni de. A Floresta da Tijuca. Rio de Janeiro: Bloch Ed., 1967.

DEAN, Warren. A ferro e fogo: A história da devastação da Mata Atlântica brasileira. São Paulo: Cia. das Letras, 1996.

DRAMSTAD, Wenche E., OLSON, James D., FORMAN, Richard T. T. Landscape ecology principles in landscape architecture and land-use planning. Washington: Island Press, 1996.

FORMAN, R., GODRON, M. Landscape ecology. Nova York: John Wiley and Sons, 1986.

FORMAN, Richard T. T., ZONNEVELD, Isaak S. Changing landscapes: An ecological perspective. Nova York: Springer-Verlag, 1990.

FORMAN, Richard T. T. Land mosaics: The ecology of landscapes and regions. Cambridge: Cambridge University Press, 1997.

HELLMUND. Paul C., SMITH, Daniel S. (org.). Ecology of greenways: Design and function of linear conservation areas. Minneapolis: University of Minnesota Press, 1993.

HOUGH, Michael. Cities and natural process. Nova York: Rutledge, 1995.

Out of place: Restoring identity to the regional landscape. New Haven: Yale University Press, 1990.

KLUNSTER, James H. Home from nowhere; remaking our everyday world for the twenty-first century. Nova York: Touchstone, 1996.

LYNCH, Kevin. Managing the sense of a region. Cambridge: The MIT Press, 1978.

MOTTA, Flávio L. Roberto Burle Marx e a nova visão de paisagem. São Paulo: Nobel, 1984.

NASSAUER, Joan I (ed.). Placing nature: Culture and landscape ecology. Washington: Island Press, 1997. 179p.

ODUM, Eugene. The strategy of ecosystem development. Science, n.164, p. 262-70, 1969.

OLIVEIRA, Ana C. M. A. de, BRITO, Yvana C. F. de. (eds.) Visualidade, urbanidade, intertextualidade. Sāo Paulo: Hacker Editores, 1998. $321 \mathrm{p}$.

PELLEGRINO, Paulo R. M. Paisagem e ambiente: Um processo de aproximação no setor oeste da macrometrópole de São Paulo. São Paulo, 1987. Dissertaçāo (Mestrado). Faculdade de Arquitetura e Urbanismo - Universidade de São Paulo.

Paisagens temáticas: Ambiente virtual. São Paulo: FAUUSP, 1995.

SCOTT, James C. Seeing like a state: How certain schemes to improve the human condition have failed. New Haven: Yale University Press, 1998.

SPIRN, Anne. O jardim de granito. São Paulo: Edusp, 1996.

STEINITZ, Carl. A framework for theory applicable to the education of landscape architects (and other design professionals). Landscape Journal, v. 9, n. 2, p. 136-143. Fall 1990.

THOMPSON, George, STEINER, Frederick. Ecological design and planning. Nova York: John Wiley \& Sons, Inc., 1997.

WALLACE, MCHARG, ROBERTS and TODD. Woodlands new community: An ecological plan. Houston - Texas: The Wodlands Development Co., 1975. 